\title{
B-50/GAP43 Is Localized at the Cytoplasmic Side of the Plasma Membrane in Developing and Adult Rat Pyramidal Tract
}

\author{
T. G. M. F. Gorgels, ${ }^{1}$ M. Van Lookeren Campagne, ${ }^{2}$ A. B. Oestreicher, ${ }^{2}$ A. A. M. Gribnau, ${ }^{1}$ and W. H. Gispen ${ }^{2}$ \\ 'Department of Anatomy and Embryology, University of Nijmegen, Nijmegen, and 'Division of Molecular Neurobiology, \\ Rudolf Magnus Institute for Pharmacology and Institute of Molecular Biology and Medical Biotechnology, University of \\ Utrecht, Utrecht, The Netherlands
}

The neuron-specific phosphoprotein B-50/GAP43 has been implicated in axonal outgrowth, since high levels of B-50/ GAP43 are found in growth cones and during development of the nervous system. In adult brain, the B-50 levels are decreased. B-50 is primarily found in axons and presynaptic terminals. It is phosphorylated by protein kinase $\mathrm{C}$, and this process has been implicated in the modulation of membrane signal transduction.

During the outgrowth of the pyramidal tract, high levels of B-50 have been reported, whereas a low amount of B-50 persists into the adult stage. By immunoelectron microscopy, using immunogold labeling on cryosections and pre-embedding peroxidase labeling, we examined the distribution of B-50 in the pyramidal tract at the third cervical segment in developing 2-d-old and adult 90-d-old rats. B-50 immunoreactivity was found in axons and growth cones of the outgrowing tract. In the adult pyramidal tract, both unmyelinated and myelinated axons contained B-50 immunoreactivity. The immunogold label was predominantly located at the plasma membrane. Since the peroxidase reaction product was observed exclusively intracellularly, we conclude that the B-50 immunoreactivity is predominantly located at the cytoplasmic side of the plasma membrane of axons and growth cones. The high immunoreactivity in growth cones and axons of the outgrowing pyramidal tract further supports the hypothesis that B-50 plays a role in neurite outgrowth. The presence of B-50 in the adult pyramidal tract cannot merely be attributed to transport to the synapse. Therefore, it is suggested that B-50 plays, in addition, a local, growth-associated role in the adult tract.

During the development of the nervous system, nerve cells extend neurites that grow over long distances, navigating by means of growth cones toward their targets to establish synaptic contacts. In the peripheral nervous system, this ability is preserved throughout life and is called on in the process of regeneration. Although in the adult mammalian CNS the capacity of axonal

\footnotetext{
Received Jan. 20, 1989; revised Mar. 27, 1989; accepted Apr. 7, 1989.

This work was supported by the Foundation for Medical and Health Research (MEDIGON), which is subsidized by the Netherlands Organization for Scientific Research (NWO). We wish to thank M. M. A. Helsen, R. Bloemen, and T. Hafmans for their expert technical assistance and the late Dr. E. J. M. De Kort for valuable suggestions.

Correspondence should be addressed to T. G. M. F. Gorgels, Department of Anatomy and Embryology, Faculty of Medicine, University of Nijmegen, P.O. Box $9101,6500 \mathrm{HB}$, Nijmegen, The Netherlands.

Copyright (C) 1989 Society for Neuroscience $0270-6474 / 89 / 113861-09 \$ 02.00 / 0$
}

growth is largely lost, modifications can occur during adult life at a smaller scale of the axonal terminal arbor and the synapse (Cotman and Nieto-Sampedro, 1984). Work on the molecular basis of these processes has shown an interesting convergence by the identification in different laboratories of a neuron-specific phosphoprotein, known as B-50, GAP43, F1, pp46, and P-57, which has been found to be involved in neuritogenesis, axon regeneration, and synaptic plasticity (Benowitz and Routtenberg, 1987).

B-50/GAP43 is a member of a small group of growth associated proteins (GAPs) (Skene and Willard, 1981; Willard et al., 1985) characterized by a dramatic increase in synthesis during axonal regeneration in nonmammalian nervous system and in vertebrate peripheral nervous system. Furthermore, high levels of B-50/GAP43 are correlated with neurite outgrowth during CNS development (Jacobson et al., 1986; Zwiers et al., 1987) and with NGF-induced neurite outgrowth in pheochromocytoma PC12 cells (Van Hooff et al., 1986, 1989). B-50 is also identical to pp46, a major phosphoprotein constituent of nerve growth cone fractions isolated from fetal rat brain (Katz et al., 1985; De Graan et al., 1985). By immunocytochemistry, B-50 has been localized in outgrowing neurites during CNS development (Oestreicher et al., 1983a; Oestreicher and Gispen, 1986; Gorgels et al., 1987; McGuire et al., 1988), in regenerating axons of peripheral nerve in situ (Verhaagen et al., 1986, 1988), and in outgrowing neurites and growth cones in vitro (Meiri et al., 1986). The expression of B-50 is developmentally regulated, and highest levels are found in neonatal rat brain (Jacobson et al., 1986; Zwiers et al., 1987). B-50 persists into the adult rat CNS. It is then predominantly located in neuropil-rich areas (Oestreicher and Gispen, 1986; Benowitz et al., 1988), where it appears to be restricted to presynaptic terminals (Gispen et al., 1985). In membranes of growth cones and outgrowing neurites isolated from fetal and postnatal rat brain and in synaptosomes, B-50 acts as a major substrate of protein kinase $\mathrm{C}$ (Oestreicher et al., 1982; De Graan et al., 1985, 1986; Van Hooff et al., 1988; Dekker et al., 1989). Phosphorylation of B-50 may serve to modulate membrane signal transduction in these structures (Gispen, 1986).

The pyramidal tract (PT) represents an adequate model system to document the relation between the expression of B-50 and the development of central nerve tracts. The ontogeny of the pyramidal tract has been widely studied, especially in rodents. The spatial and temporal outgrowth of its fibers in the spinal cord have been described (e.g., in the rat: Schreyer and Jones, 1982; Gribnau et al., 1986; in the hamster: Reh and Kalil, 1981). Concurrent with its proposed role in neurite outgrowth, 
high levels of B-50/GAP43 have been reported during the outgrowth of the PT in the rat and in the hamster (Kalil and Skene, 1986; Gorgels et al., 1987). Although low levels of B-50 persist into the adult stage, the failure of the adult PT to regenerate has been correlated with a lack of increase of B-50/GAP43 synthesis on transection of the mature tract (Kalil and Skene, 1986; Reh et al., 1987). In the present study, we analyzed by immunocytochemistry the ultrastructural localization of B50 in the outgrowing PT as well as in the adult PT.

\section{Materials and Methods}

Animals and tissue processing. Two-d-old and adult (90-d-old) Wistar rats were anesthetized by intraperitoneal injection of an aqueous solution of sodium pentobarbital and perfused intracardially with a fixative consisting of $2 \%$ paraformaldehyde and $2 \%$ glutaraldehyde in 0.1 M phosphate buffer, $\mathrm{pH}$ 7.4. The third cervical spinal cord segment was then removed and immersed overnight in the fixative at $4^{\circ} \mathrm{C}$. Experiments were also carried out with a fixative containing $0.5 \%$ glutaraldehyde instead of $2 \%$ glutaraldehyde, without apparent change in immunoreactivity. For pre-embedding peroxidase immunocytochemistry, $50 \mu \mathrm{m}$ thick transverse Vibratome sections were cut of this segment into chilled Tris-buffered saline (TBS: $0.1 \mathrm{~m}$ Tris, $0.9 \% \mathrm{NaCl}, \mathrm{pH} 7.6$ ). For cryoultramicrotomy, the tissue segments were stored up to $4 \mathrm{~d}$ in $1 \%$ paraformaldehyde in PBS $(0.1 \mathrm{M}$ phosphate buffer, containing $0.9 \%$ $\mathrm{NaCl}, \mathrm{pH}$ 7.4) until further processing.

Pre-embedding peroxidase labeling. Free-floating Vibratome sections were incubated in $5 \%$ normal goat serum in TBS containing $0.1 \%$ BSA (TBS/BSA) for 30 min. Next, the sections were rinsed in TBS/BSA (3 times $5 \mathrm{~min}$ ) and incubated for $48 \mathrm{hr}$ at $4^{\circ} \mathrm{C}$ in affinity-purified rabbit anti B-50 immunoglobulins (a-B-50 IgGs of rabbit 8420) (Oestreicher et al., 1983b; Oestreicher and Gispen, 1986), diluted 1:8000 in TBS/ BSA. Control sections were incubated in TBS/BSA or in preimmune IgGs diluted in TBS/BSA. Immunodetection was performed using the avidine biotin procedure (ABC kit, Vector). Sections were rinsed in TBS/BSA ( 3 times $5 \mathrm{~min}$ ) and incubated for $90 \mathrm{~min}$ in biotinylated goat antirabbit antibodies in TBS/BSA and subsequently, after rinsing in buffer, in avidine-HRP complex in TBS/BSA for $90 \mathrm{~min}$. Next, the sections were rinsed in buffer and incubated in $0.05 \%$ diaminobenzidine tetrahydrochloride (DAB) in $0.05 \mathrm{M}$ Tris- $\mathrm{HCl}$ buffer, $\mathrm{pH} 7.6$, containing $0.01 \%$ hydrogen peroxide. The staining reaction was terminated after $5 \mathrm{~min}$ by rinsing the sections in TBS. Some sections were washed in bidistilled water, mounted on glass slides, and embedded in Entellan for light microscopic analysis. Other sections were postfixed for $1 \mathrm{hr}$ in $1 \% \mathrm{OsO}_{4}, 1.5 \% \mathrm{~K}_{4} \mathrm{FeCN}_{6}$ in $0.1 \mathrm{M}$ phosphate buffer, $\mathrm{pH}$ 7.4. After rinsing in phosphate buffer and in bidistilled water, the sections were stained en bloc in $0.5 \%$ aqueous uranyl acetate for $1 \mathrm{hr}$. Sections were dehydrated in an ascending series of ethanol and in propylene oxide, transferred into a mixture of propylene oxide and Epon (1:1) for $2 \mathrm{hr}$, and left overnight in Epon. The sections were flat embedded in Epon between slides coated with Repelcoat (dimethyldichlorsilane). After polymerization, the tissue was reembedded on Epon blocks, and ultrathin sections were cut. The sections were not counterstained and were analyzed in a Philips EM 300 electron microscope at an accelerating voltage of 60 $\mathrm{kV}$.

Immunogold labeling of cryosections. The tissue segments were rinsed in PBS and incubated for $1 \mathrm{hr}$ in 5\% gelatin in PBS in small Eppendorf cups at $37^{\circ} \mathrm{C}$. The gelatin containing the tissue blocks was fixed overnight in $2 \%$ paraformaldehyde, $2 \%$ glutaraldehyde in PBS, and the PT was dissected out using a razor blade. After immersion in $1.15 \mathrm{~m}$ sucrose, $15 \%$ polyvinyl-pyrrolidone-10 (PVP) in PBS, the tissue was rapidly frozen in liquid nitrogen. Transverse ultrathin cryosections were cut at $-100^{\circ} \mathrm{C}$ on a Reichert Ultracut microtome (Tokuyasu, 1984). Sections were picked up from the knife and mounted on nickel grids using a drop of $2.3 \mathrm{M}$ sucrose in PBS. The grids were rinsed on drops of PBS containing $50 \mathrm{~mm}$ glycine and on drops of PBG $(0.1 \%$ gelatin, $0.5 \%$ BSA in PBS) and incubated overnight at $4^{\circ} \mathrm{C}$ in affinity-purified rabbit antiB-50 IgGs (of rabbit 8613; Oestreicher et al., 1983b; Oestreicher and
Gispen, 1986) diluted 1:300 in PBG. Control sections were incubated in PBG or in preimmune IgGs diluted in PBG. Next, the grids were rinsed in PBG and incubated in goat antirabbit conjugated gold (GARgold, diameter $9.3 \mathrm{~nm}$; Van Bergen en Henegouwen and Leunissen, 1986) in PBG for $1 \mathrm{hr}$. After rinsing in bidistilled water, the grids were incubated for $10 \mathrm{~min}$ in $1.1 \%$ tylose, $0.5 \%$ uranyl acetate, $\mathrm{pH} 4.0$, on ice. The grids were air-dried and examined in a Philips EM 300 electron microscope at $60 \mathrm{kV}$.

For both immunolabeling procedures, at least 2 animals per age group were examined, giving similar results.

\section{Results}

Light microscopic examination of the Vibratome sections confirmed the developmental pattern in B-50 expression in the spinal cord as has been described previously using different techniques (Gorgels et al., 1987). In the 2-d-old rat, immunoreactivity was high in the gray and even higher in the white matter, whereas in the adult rat, the immunoreactivity was greatly reduced, especially in the white matter. In this study, we focused on the expression of B-50 in the PT during its outgrowth phase (at P2) and at the mature stage (at $90 \mathrm{~d}$ of age). In the 2-d-old rat, high immunoreactivity was present in the dorsal funiculus, including the PT (Fig. 1A). The posterior median septum consisting of glial cells was not stained. In the 3-month-old rat, the immunoreactivity was greatly reduced in the dorsal funiculus, but in contrast to the ascending tracts, the PT still displayed a reduced but distinct immunoreactivity (Fig. $1 B$ ).

\section{Immunoelectron microscopy of the outgrowing pyramidal tract}

The ultrastructure of the developing cervical PT in the rat has been described by De Kort et al. (1985). The bundle consists of small, unmyelinated axons and interlaced glial elements. At their distal ends, the axons bear growth cones characterized by their larger diameter, the presence of vesicles, and a meshwork of smooth endoplasmic reticulum. Distally, these growth cones taper into filopodia.

At the electron microscopic level, the immunoreaction for B-50 in the sections stained with the pre-embedding technique was revealed by the presence of the electron-dense osmicated DAB reaction product. The intensity of immunolabeling was greatest on the surface of the Vibratome sections and decreased with depth. The maximal penetration of the immunoreaction was $4-5 \mu \mathrm{m}$. In ultrathin sections close to the surface of the Vibratome sections of the 2-d-old rat, practically all PT axons were heavily stained, whereas glial cell bodies and their processes were not stained (Fig. $2 A$ ). Growth cones and filopodia were more readily identified in less superficial sections, since in these sections, the intensity of the immunoreaction was reduced and more intracellular details could be discerned (Fig. 2, $B, C$, $D$ ). In these tissue sections containing slices of labeled growth cones, the rcaction product was predominantly dcposited near the plasma membrane, whereas the meshwork of smooth endoplasmic reticulum in the central region of the growth cone showed no immunoreaction (Fig. 2, B, C). In filopodia, the reaction product was deposited throughout the whole cytosolic compartment (Fig. 2D). No reaction product was detected extracellularly.

In the cryosections stained with the immunogold technique, all axons in the PT of the 2-d-old rat were labeled (Fig. 3A). To

Figure 1. Distribution of B-50 immunoreactivity as detected with the PAP method in transverse Vibratome sections of the third cervical segment in the 2-d-old rat $(A)$ and in the 90-d-old rat $(B)$. In the 2-d-old rat, intense immunoreactivity was found in the dorsal funiculus, where the $P T$ 
A

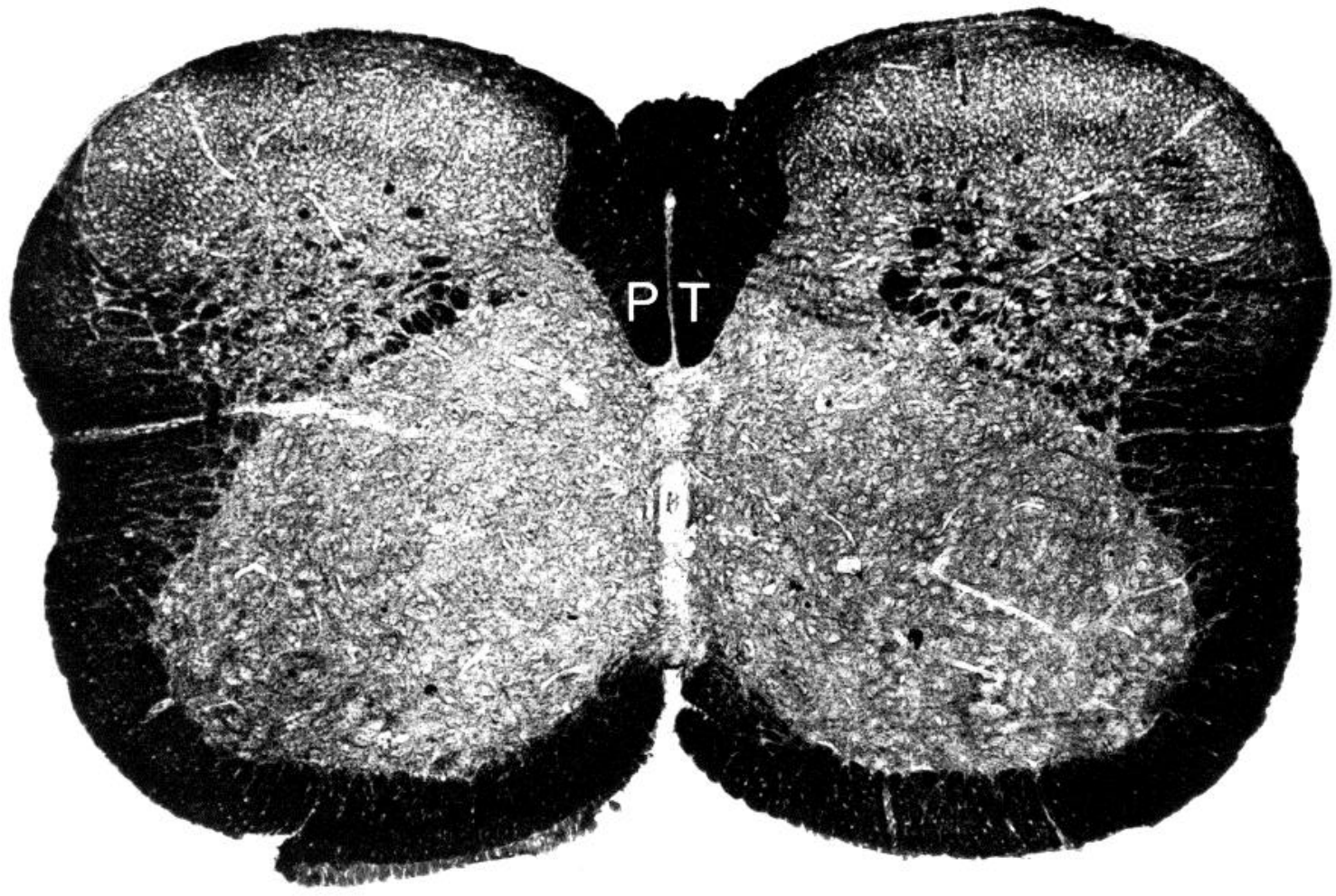

B

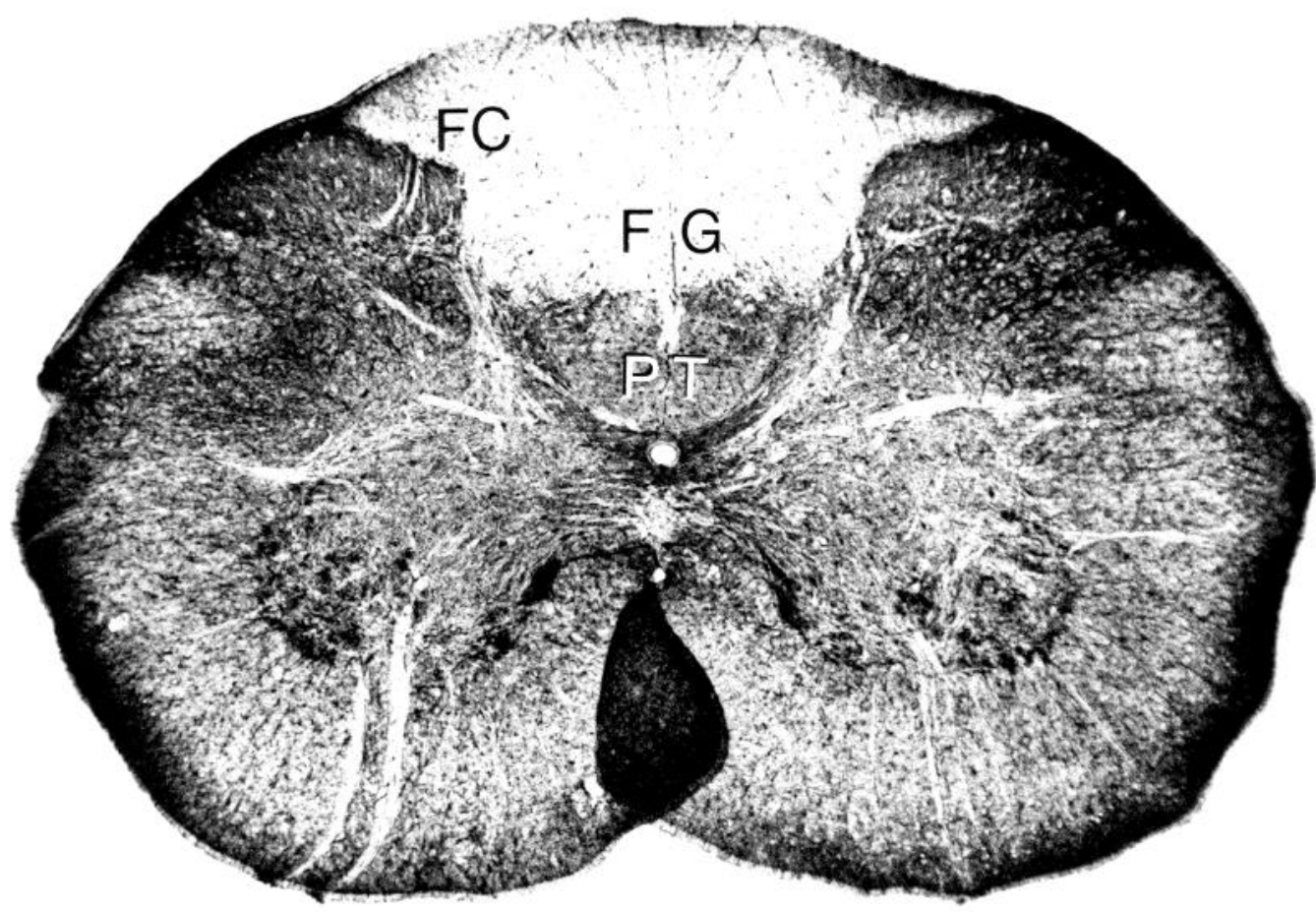

occupies the ventralmost position. In the adult rat, the immunoreactivity in the dorsal funiculus was greatly reduced. Some immunoreactivity persisted, however, in the PT, whereas the ascending sensory tracts in the dorsal funiculus, the fasciculus gracilis $(F G)$, and the fasciculus cuneatus $(F C)$ were essentially negative. Scale bars, $0.25 \mathrm{~mm}(A)$ and $0.5 \mathrm{~mm}(B)$. 

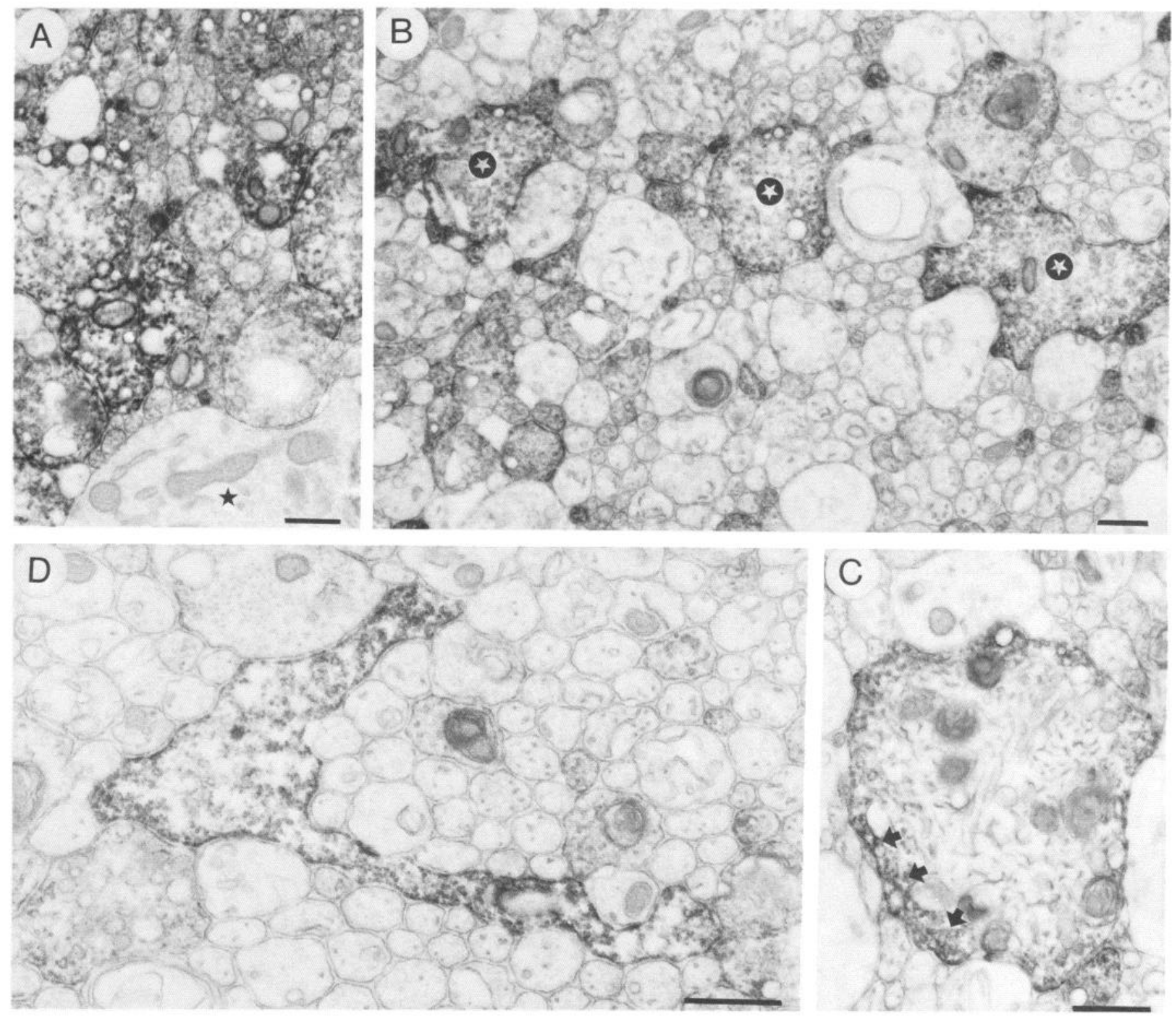

Figure 2. Immunoelectron microscopic localization of B-50 in the PT at the third cervical segment in the 2-d-old rat, using pre-embedding peroxidase labeling. In ultrathin sections taken close to the surface of the Vibratome section $(A)$, essentially all axons were intensely labeled, whereas the glial elements (black asterisk) were devoid of label. In less superficial sections, the intensity of the immunoreaction was reduced, and labeled growth cones $(B$, white asterisk; $C)$ and filopodia $(D)$ could be identified. The reaction product was deposited in growth cones near the plasma membrane $(C)$, whereas in the filopodia, it was detected also in the cytosol $(D)$. No label was observed extracellularly. Scale bars, $0.5 \mu \mathrm{m}$.

a great extent, the label was located at the axolemna. In growth cones similarly, the majority of the gold particles were located at the plasma membrane (Fig. 3C). Occasionally, some label was encountered in the cytoplasm of axons and growth cones. Although this label sometimes was found close to vesicles, no consistent labeling of vesicles was observed. Mitochondria were mostly free of immunolabeling. The meshwork of agranular reticulum in the central part of the growth cone showed hardly any label. Filopodia could not unambiguously be identified in the cryosections. Control sections incubated in the preimmune serum (Fig. $3 B$ ) or in buffer showed only a few scattered gold particles.

\section{Immunoelectron microscopy of the adult PT}

The mature PT contains, in addition to myelinated axons, unmyelinated axons (Leenen et al., 1982; Joosten and Gribnau, 1988; Gorgels et al., 1989). In the mature PT stained with the pre-embedding technique, the intensity of the immunoreaction

Figure 3. Immunogold labeling of cryosections of the 2-d-old PT, using GAR-gold particles (9.3 nm) following incubation with affinity purified anti-B-50 IgGs $(A, C)$ or with preimmune IgGs as negative control $(B)$. The gold particles were mainly located at the axolemna of the axons $(A)$. Note the absence of label in sections stained with preimmune IgGs $(B)$. In growth cones $(C$, asterisks) similarly, the majority of gold particles was found at the plasma membrane. Some label was observed in the cytoplasm of axons and growth cones. Scale bars, $0.5 \mu \mathrm{m}$. 


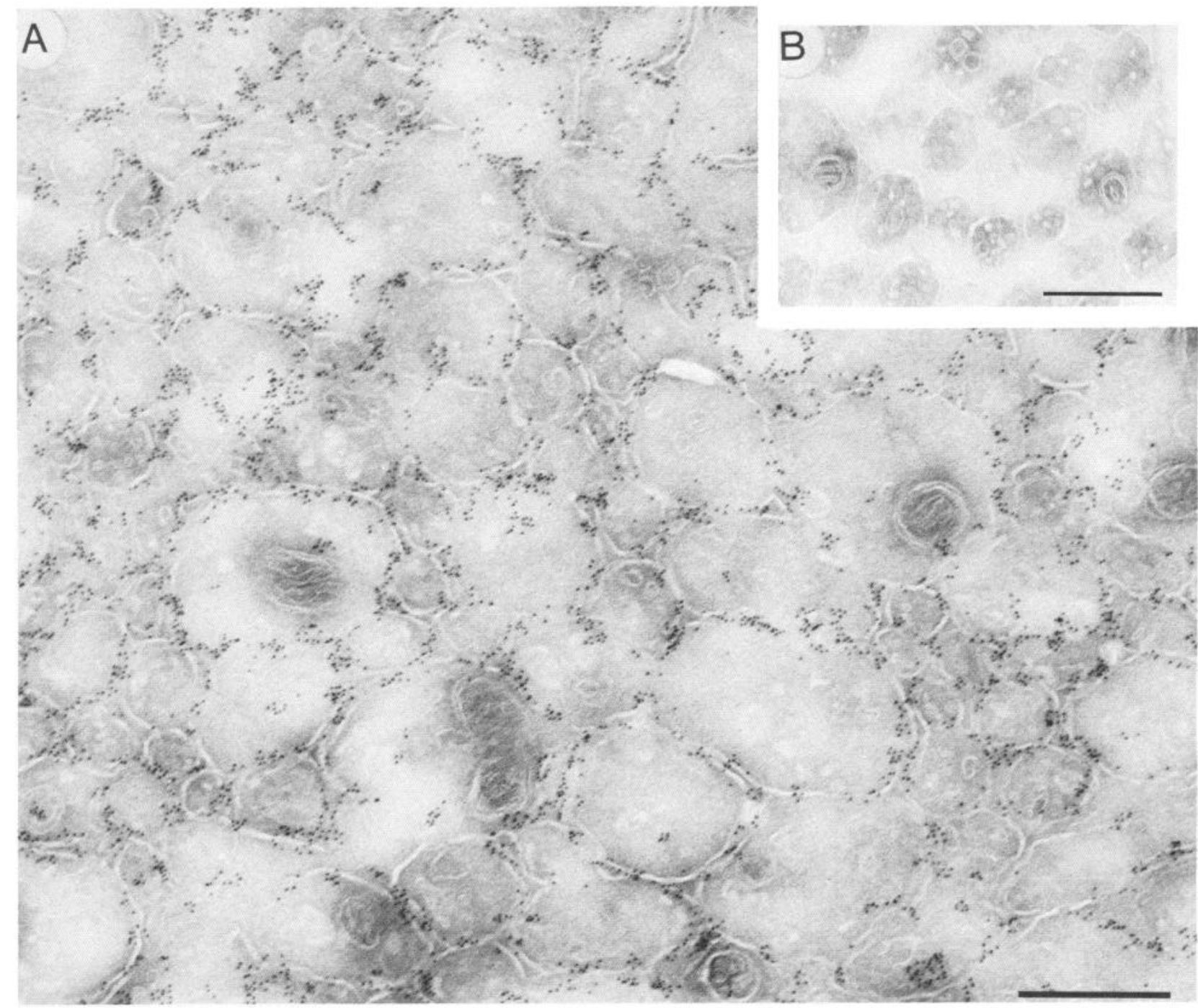

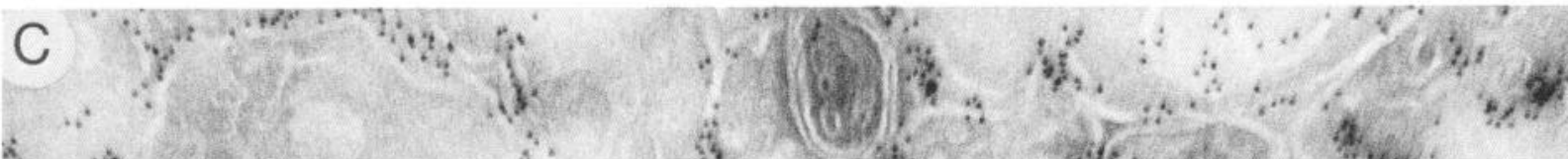
$3, \ldots$

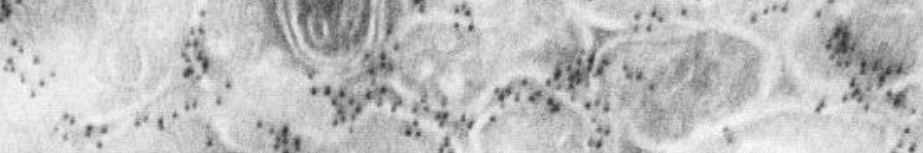

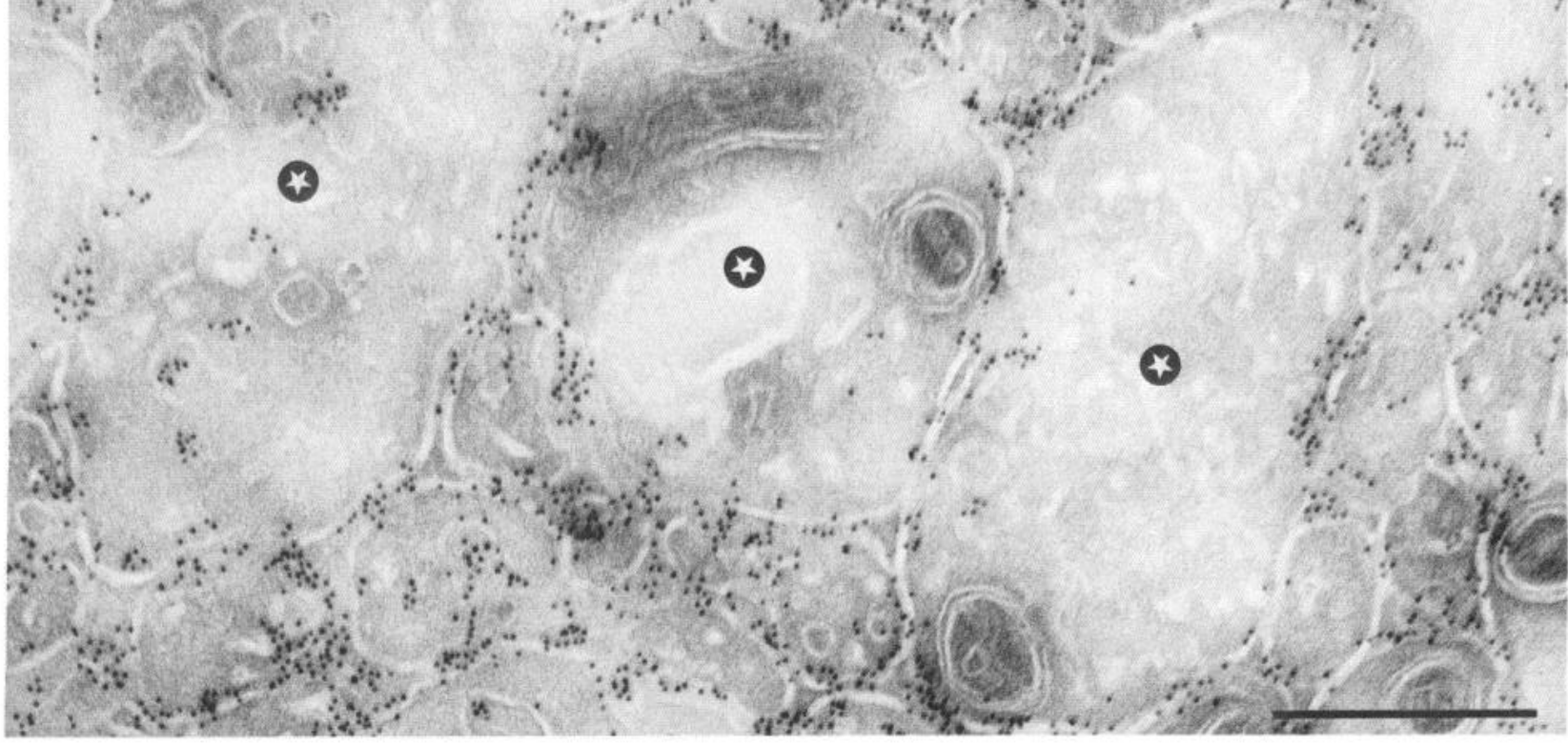


Figure 4. B-50 immunoreactivity in the adult PT detected with pre-embedding peroxidase labeling. Staining was observed in unmyelinated (arrows) as well as in myelinated axons $(A)$. Large myelinated axons were not stained. The reaction product was contained within the axon $(B)$. Astrocyte process (asterisk) was not stained. Scale bars, $0.5 \mu \mathrm{m}$ $(A)$ and $0.1 \mu \mathrm{m}(B)$.
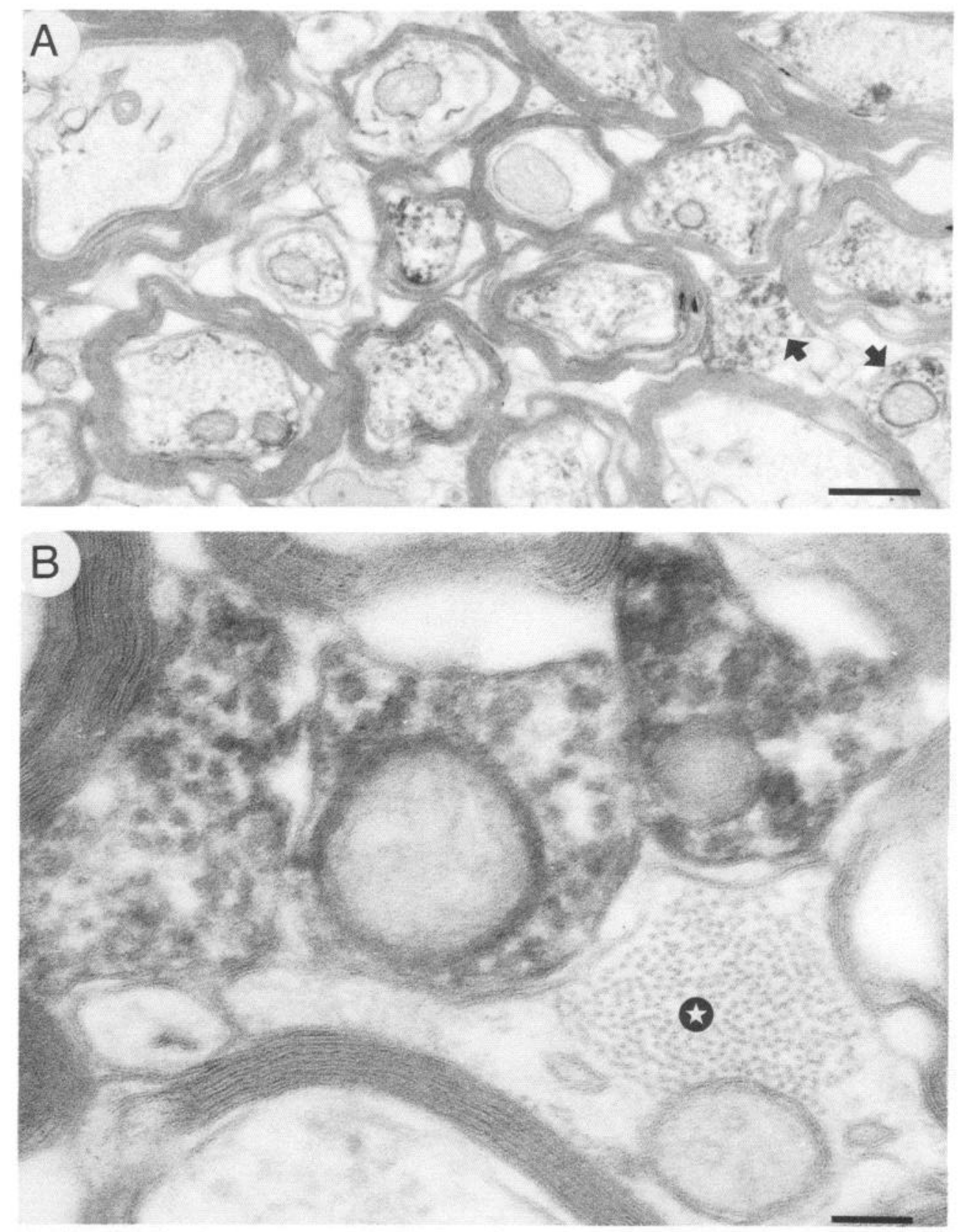

even in superficial layers of the Vibratome sections was reduced as compared to the early postnatal PT. Even so, many unmyelinated axons as well as myelinated axons were stained (Fig. 4). The reaction product was exclusively contained within the axons, indicating that the antigen is located intracellularly. The intensity of the immunoreaction varied greatly. In general, however, large myelinated axons (diameter $>1 \mu \mathrm{m}$ ) (Gorgels et al., 1989) were hardly stained. Processes of astrocytes and oligodendrocytes were not labeled.

The immunogold technique applied to the cryosections of the adult PT showed B-50 immunoreactivity predominantly at the axolemna of unmyelinated and myelinated axons. In addition, some label was encountered in the axoplasm (Fig. 5). Although occasionally the cytoplasmic label was found close to vesicles, in general no specific association with organelles was apparent. Practically all axons were labeled. The intensity of the immu- nolabeling was quite variable. On screening many sections, it appeared that the largest myelinated axons ( $>1 \mu \mathrm{m})$ were less intensely labeled.

\section{Discussion}

Previous studies on B-50 expression in the PT have shown that during the outgrowth of its fibers high levels of B-50 are present in the tract, and some B-50 persists into the adult stage (Kalil and Skene, 1986; Gorgels et al., 1987). In the present study, this general developmental pattern was corroborated, and in addition, the ultrastructural localization of B-50 was established using immunogold labeling on cryosections and pre-embedding peroxidase labeling. The results of both techniques demonstrate B-50 immunoreactivity in axons and growth cones of the outgrowing PT, as well as in unmyelinated and myelinated axons 


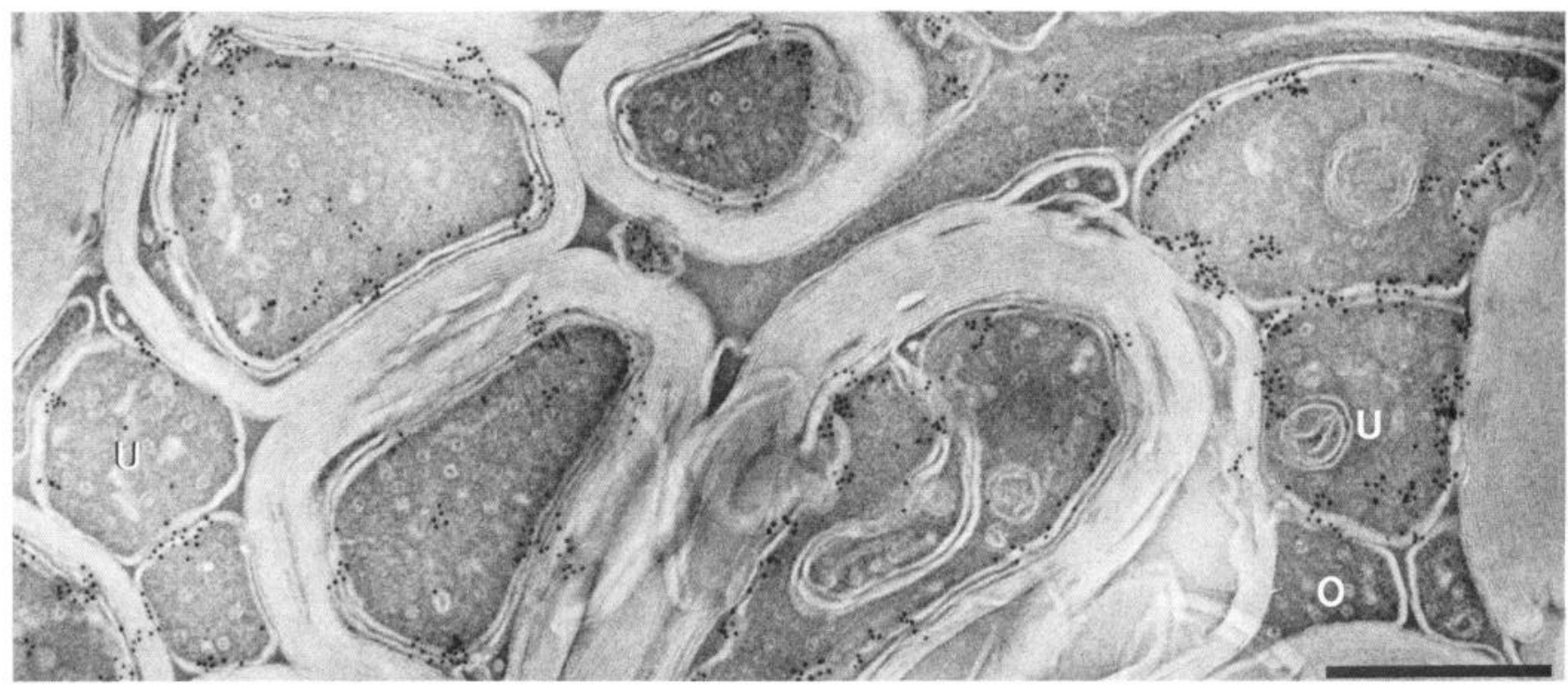

Figure 5. Immunogold labeling of B-50, using GAR-gold particles $(9.3 \mathrm{~nm})$ in cryosections of the adult rat PT at the third cervical segment. Unmyelinated as well as myelinated axons were stained predominantly, although not exclusively at the plasma membrane. Virtually no label was observed on oligodendrocyte processes. $O$, outer tongue process. Scale bar, $0.5 \mu \mathrm{m}$.

of the adult tract. By immunogold labeling, we found that immunoreactivity was located predominantly at the plasma membrane of axons as well as growth cones. Since with the preembedding peroxidase technique no label was detected extracellularly and because the primary structure of B-50 contains no membrane spanning domain (Nielander et al., 1987), we conclude that $\mathrm{B}-50$ is predominantly located at the cytoplasmic side of the plasma membrane.

Localization of the antigen by immunocytochemistry depends on the antibody and the method specificity. The latter was tested by incubation with the preimmune serum and with buffer. The specificity of the affinity-purified antibodies has been characterized in previous studies (Oestreicher et al., 1983a, b; Oestreicher and Gispen, 1986; Van Hooff et al., 1988, 1989; Van Lookeren Campagne et al., 1989). The polyclonal antibodies used in the present study recognize B-50 irrespective of its phosphorylation state (Oestreicher et al., 1986; De Graan et al., 1989) and irrespective of its binding to calmodulin (A. B. Oestreicher and P. N. E. De Graan, unpublished observations). We, therefore, think that the distribution of B-50 immunoreactivity corresponds to the actual distribution of B-50 in the rat PT (Oestreicher et al., 1986).

By immunocryoultramicrotomy, B- 50 has been localized at the cytoplasmic face of the plasma membrane in presynaptic terminals, synaptosomes, and nerve growth cone particles (Gispen et al., 1985; Van Lookeren Campagne et al., 1989). The present in situ study indicates that this localization also holds true for growth cones and myelinated and unmyelinated axons in the PT. B-50 also is present in filopodia, as shown by peroxidase labeling. Since the DAB reaction product generated by the peroxidase technique can diffuse away from the site of generation (Courtoy et al., 1983), the subcellular localization of B-50 within the filopodia could not be determined. Van Hooff et al. (1989) showed that in filopodia of outgrowing neurites of $\mathrm{PC} 12$ cells, B-50 is also predominantly associated with the inner side of the plasma membrane.

Apart from the localization at the plasma membrane, a small fraction of the B-50 immunoreactivity was found in the cytoplasm of growth cones and axons. Although some of this cytoplasmic label might be associated with vesicles, in general, no specific association with organelles could be determined. Similar observations were made by Van Lookeren Campagne et al. (1989), studying isolated growth cones and synaptosomes. A possible explanation for this cytosolic B-50 comes from a recent study by Skene and Virág (1989), who showed that B-50/GAP43 maintains reversible interactions with the growth cone membrane by fatty acylation, probably of the cysteine residues at the amino terminus. On the other hand artifactual dissociation of the highly hydrophilic B-50 (Nielander et al., 1987) during the fixation and the immunocytochemical procedure cannot be ruled out.

The high immunoreactivity in the outgrowing PT supports the hypothesis that B-50 is important for axon growth. Furthermore, the B-50 localization in the growth cone suggests a role for B-50 in neurite elongation and target-directed navigation (Lockerbie, 1987). Biochemical experiments on synaptosomes and growth cone particles have indicated that B-50 is a prominent substrate of protein kinase $C$, which is shown to be activated as a result of receptor-mediated hydrolysis of phosphatidyl inositol bisphosphate (Van Hooff et al., 1988; Dekker et al., 1989). In this neuronal membrane signal transduction, phosphorylation of B-50 is supposed to serve as a negative feedback control by inhibition of the membrane-associated PIP kinase (Gispen, 1986). The localization of B-50 at the cytoplasmic side of the plasma membrane agrees well with this model. Another mechanism of B-50 function is suggested by the identity of B-50 to P-57, an atypical calmodulin binding protein, which releases calmodulin and then can be phosphorylated (Cimler et al., 1987). The importance of calmodulin and local $\mathrm{Ca}^{2+}$ levels on nerve growth cone functioning has been well documented (Lockerbie, 1987; Kater et al., 1988).

Previous studies on the localization of B-50 in the adult rat brain have emphasized its localization in neuropil-rich areas (Oestreicher and Gispen, 1986; Oestreicher et al., 1986; Be- 
nowitz et al., 1988; McGuire et al., 1988), particularly in presynaptic terminals (Gispen et al., 1985). Nonetheless, in the adult PT, some B-50 immunoreactivity remains present in unmyelinated and myelinated axons. Part of this immunoreactivity might reflect transport of B-50 to the synapse. In addition, however, the predominant localization of B-50 at the axolemna of unmyelinated and myelinated axons suggests a local role for B-50 within the adult PT. Interestingly, the distribution of protein kinase $\mathrm{C}$ in the dorsal funiculus of the rat cervical spinal cord is very similar to that of B-50, the ascending fiber tracts being essentially devoid of immunoreactivity and the PT being moderately densely stained (Saito et al., 1988). The function of B-50 in the adult rat PT is unknown. The implication of B-50 in axonal growth and our observation that the largest myelinated axons are less B-50 immunoreactive suggest that $\mathrm{P} \mathrm{I}$ axons retain a neuroplastic capacity for increase in diameter, elongation, or possibly sprouting.

\section{References}

Benowitz, L. I., and A. Routtenberg (1987) A membrane phosphoprotein associated with neural development, axonal regeneration, phospholipid metabolism, and synaptic plasticity. Trends Neurosci. 10: 527-532.

Benowitz, L. I., P. J. Apostolides, N. Perrone-Bizzozero, S. P. Finklestein, and H. Zwiers (1988) Anatomical distribution of the growthassociated protein GAP-43/B-50 in the adult rat brain. J. Neurosci. 8: 339-352.

Cimler, B. M., D. H. Giebelhaus, B. T. Wakim, D. R. Storm, and R. T. Moon (1987) Characterization of murine cDNAs encoding P-57, a neural-specific calmodulin-binding protein. J. Biol. Chem. 262: 12158-12163.

Cotman, C. W., and M. Nieto-Sampedro (1984) Cell biology of synaptic plasticity. Science 225: 1287-1294.

Courtoy, P. J., D. H. Picton, and M. G. Farquhar (1983) Resolution and limitations of the immunoperoxidase procedure in the localization of extracellular matrix antigens. J. Histochem. Cytochem. 31: 945-951.

De Graan, P. N. E., C. O. M. Van Hooff, B. C. Tilly, A. B. Oestreicher, P. Schotman, and W. H. Gispen (1985) Phosphoprotein B-50 in nerve growth cones from fetal rat brain. Neurosci. Lett. 61: 235-241.

De Graan, P. N. E., A. B. Oestreicher, L. H. Schrama, and W. H. Gispen (1986) Phosphoprotein B-50: Localization and function. Prog. Brain Res. 69: 37-50.

De Graan, P. N. E., A. B. Oestreicher, L. V. Dekker, L. Van der Voorn, and W. H. Gispen (1989) Determination of changes in the phosphorylation state of the neuron-specific protein kinase $C$ substrate B-50 (GAP43) by quantitative immunoprecipitation. J. Neurochem. 52: 17-23.

Dekker, L. V., P. N. E. De Graan, D. H. G. Versteeg, A. B. Oestreicher, and W. H. Gispen (1989) Chemical depolarization stimulates B-50/ GAP43 phosphorylation in rat brain synaptosomes. Abstract of the 12th meeting of I.S.N., n'S 106D. J. Neurochem. (in press).

De Kort, E. J. M., A. A. M. Gribnau, H. T. H. Van Aanholt, and R. Nieuwenhuys (1985) On the development of the pyramidal tract in the rat. I. The morphology of the growth zone. Anat. Embryol. 172: 195-204.

Gispen, W. H. (1986) Phosphoprotein B-50 and phosphoinositides in brain synaptic plasma membranes: A possible feedback relationship. Trans. Biochem. Soc. Trans. UK 14: 163-165.

Gispen, W. H., J. L. M. Leunissen, A. B. Oestreicher, A. J. Verkleij, and $H$. Zwiers (1985) Presynaptic localization of B-50 phosphoprotein: The (ACTH)-sensitive protein kinase substrate involved in rat brain polyphosphoinositide metabolism. Brain Res. 328: 381385.

Gorgels, T. G. M. F., A. B. Oestreicher, E. J. M. De Kort, and W. H. Gispen (1987) Immunocytochemical distribution of the protein kinase C substrate B-50 (GAP43) in the developing rat pyramidal tract. Neurosci. Lett. 83: 59-64.

Gorgels, T. G. M. F., E. J. M. de Kort, H. T. H. Van Aanholt, and R. Nieuwenhuys (1989) A quantitative analysis of the development of the pyramidal tract in the cervical spinal cord in the rat. Anat. Embryol. 179: 377-385.

Gribnau, A. A. M., E. J. M. De Kort, P. J. W. C. Dederen, and R. Nieuwenhuys (1986) On the development of the pyramidal tract in the rat. II. An anterograde tracer study of the outgrowth of the corticospinal fibers. Anat. Embryol. 175: 101-1 10.

Jacobson, R. D., I. Virag, and J. H. P. Skene (1986) A protein associated with axon growth, GAP-43, is widely distributed and developmentally regulated in rat CNS. J. Neurosci. 6: 1843-1855.

Joosten, E. A. J., and A. A. M. Gribnau (1988) Unmyelinated corticospinal axons in the adult rat pyramidal tract. An electron microscopic tracer study. Brain Res. 459: 173-177.

Kalil, K., and J. H. P. Skene (1986) Elevated synthesis of an axonally transported protein correlates with axon outgrowth in normal and injured pyramidal tracts. J. Neurosci. 6: 2563-2570.

Kater, S. B., M. P. Mattson, C. Cohan, and J. Connor (1988) Calcium regulation of the neuronal growth cone. Trends Neurosci. 11:315321.

Katz, F., L. Ellis, and K. H. Pfenninger (1985) Nerve growth cones isolated from fetal rat brain. III. Calcium-dependent protein phosphorylation. J. Neurosci. 5: 1402-1411.

Leenen, L., J. Meek, and R. Nieuwenhuys (1982) Unmyelinated fibers in the pyramidal tract: A new view. Brain Res. 246: 297-301.

Lockerbie, R. O. (1987) The neuronal growth cone: A review of its locomotory, navigational and target recognition capabilities. Neuroscience 20: 719-729.

McGuire, C. B., G. J. Snipes, and J. J. Norden (1988) Light-microscopic immunolocalization of the growth- and plasticity-associated protein GAP-43 in the developing rat brain. Dev. Brain Res. 41: 277291.

Meiri, K. F., K. H. Pfenninger, and M. B. Willard (1986) Growthassociated protein, GAP43, a polypeptide that is induced when neurons extend axons, is a component of growth cones and corresponds to pp46, a major polypeptide of a subcellular fraction enriched in growth cones. Proc. Natl. Acad. Sci. USA 83: 3537-3541.

Nielander, H. B., L. H. Schrama, A. J. Van Rozen, M. Kasperaitis, A. B. Oestreicher, P. N. E. De Graan, W. H. Gispen, and P. Schotman (1987) Primary structure of the neuron-specific phosphoprotein B-50 is identical to growth associated protein GAP-43. Neurosci. Res. Commun. 1: 163-172.

Oestreicher, A. B., and W. H. Gispen (1986) Comparison of the immunocytochemical distribution of the phosphoprotein B-50 in the cerebellum and hippocampus of immature and adult rat brain. Brain Res. 375: 267-279.

Oestreicher, A. B., H. Zwiers, W. H. Gispen, and S. Roberts (1982) Characterization of infant rat cerebral cortical membrane proteins phosphorylated in vivo: Identification of the ACTH-sensitive phophoprotein B-50. J. Neurochem. 39: 683-692.

Oestreicher, A. B., H. Zwiers, J. L. M. Leunissen, A. J. Verkleij, and W. H. Gispen (1983a) Localization of B-50 protein in rat brain studied by immuno-light and electron microscopy. Abstract of the $9^{\text {th }}$ meeting of the I.S.N., $n^{\circ}$ S 95A. J. Neurochem. 42 (Suppl.).

Oestreicher, A. B., C. J. Van Dongen, H. Zwiers, and W. H. Gispen (1983b) Affinity-purified anti-B-50 protein antibody: Interference with the function of the phosphoprotein B-50 in synaptic plasma membranes. J. Neurochem. 41: 331-340.

Oestreicher, A. B., L. V. Dekker, and W. H. Gispen (1986) A radioimmunoassay for the phosphoprotein B-50: Distribution in rat brain. J. Neurochem. 45: 1366-1369.

Reh, T., and K. Kalil (1981) Development of the pyramidal tract in the hamster. I. A light microscopic study. J. Comp. Neurol. 200:5567.

Reh, T. A., J. D. Redshaw, and M. A. Bisby (1987) Axons of the pyramidal tract do not increase their transport of growth-associated proteins after axotomy. Mol. Brain Res. 2: 1-6.

Saito, N., U. Kikkawa, Y. Nishizuka, and C. Tanaka (1988) Distribution of protein kinase $\mathrm{C}$-like immunoreactive neurons in rat brain. J. Neurosci. 8: 369-382.

Schreyer, D. J., and E. G. Jones (1982) Growth and target finding by axons of the corticospinal tract in prenatal and postnatal rats. Neuroscience $7: 1837-1853$.

Skene, J. H. P., and M. Willard (1981) Changes in axonally transported proteins during axon regeneration in toad retinal ganglion cells. J. Cell Biol. 89: 86-95.

Skene, J. H. P., and I. Virág (1989) Posttranslational membrane at- 
tachment and dynamic fatty acylation of a neuronal growth cone protein, GAP-43. J. Cell Biol. 108: 613-624.

Tokuyasu, K. T. (1984) Immunocryoultramicroscopy. In Immunolabeling for Electronmicroscopy, J. M. Polak and I. M. Varndell, eds. pp. 71-82, Elsevier, Amsterdam.

Van Bergen en Henegouwen, P. M. P., and J. L. M. Leunissen (1986) Controlled growth of colloidal gold particles and implications for labeling efficiency. Histochemistry 85: 81-87.

Van Hooff, C. O. M., P. N. E. De Graan, J. Boonstra, A. B. Oestreicher M. H. Schmidt-Michels, and W. H. Gispen (1986) Nerve growth factor enhances the level of the protein kinase C substrate B-50 in pheochromocytoma PC12 cells. Biochem. Biophys. Res. Commun. 139: 644-651.

Van Hooff, C. O. M., P. N. E. De Graan, A. B. Oestreicher, and W. H. Gispen (1988) B-50 phosphorylation and polyphosphoinositide metabolism in nerve growth cone membranes. J. Neurosci. 8: 17891795.

Van Hooff, C. O. M., J. Holthuis, A. B. Oestreicher, J. Boonstra, P. N. E. De Graan, and W. H. Gispen (1989) Nerve growth factor-induced changes in the intracellular localization of the protein kinase $\mathrm{C}$ substrate B-50 in pheochromocytoma PCl 2 cells. J. Cell Biol. 108: $1115-$ 1125 .
Van Lookeren Campagne, M., A. B. Oestreicher, P. M. P. Van Bergen en Henegouwen, and W. H. Gispen (1989) Ultrastructural immunocytochemical localization of B-50/GAP43, a protein kinase C substrate, in isolated presynaptic nerve terminals and neuronal growth cones. J. Neurocytol. (in press).

Verhaagen, J., C. O. M. Van Hooff, P. M. Edwards, P. N. E. De Graan, A. B. Oestreicher, P. Schotman, F. G. I. Jennekens, and W. H. Gispen (1986) The kinase C substrate protein B-50 and axonal regeneration. Brain Res. Bull. 17: 737-741.

Verhaagen, J., A. B. Oestreicher, P. M. Edwards, H. Veldman, F. G. J. Jennekens, and W. H. Gispen (1988) Light- and electron-microscopal study of the phosphoprotein B-50 following denervation and reinnervation of the rat soleus muscle. J. Neurosci. 8: 1759-1766.

Willard, M. B., K. Meiri, and H. Glicksman (1985) Changes of state during neuronal development: Regulation of axon elongation. In $\mathrm{Mo}$ lecular Basis of Neural Development, G. M. Edelman, W. E. Gall, and W. M. Cowan, eds., pp. 341-361, Wiley, New York.

Zwiers, H., A. B. Oestreicher, M. A. Bisby, P. N. E. De Graan, and W. H. Gispen (1987) Protein kinase C substrate B-50 in adult and developing rat brain is identical to axonally transported GAP-43 in regenerating peripheral rat nerve. In Axonal Transport, R. S. Smith and M. A. Bisby, eds., pp. 421-433, Liss, New York. 